\title{
A 63-year-old male with hypercapnic respiratory failure and haemoptysis
}

\section{Case report}

A 63-year-old male was admitted to the emergency department with cough, purulent sputum, dyspnoea, fatigue, haematemesis and melaena. The patient immediately underwent gastroscopy, and endoscopic sclerotherapy was performed on an actively bleeding duodenal ulcer.

The patient had a 60-pack-year smoking history, but had ceased smoking 3 years previously. Three years before admission, he was diagnosed with chronic obstructive pulmonary disease (COPD) and had been prescribed medical therapy. Severe respiratory distress developed after sclerotherapy, with dyspnoea, cyanosis, diaphoresis and agitation.

\section{Physical examination}

Initial physical examination revealed that he was conscious, cachectic with barrel chest, dyspnoeic and using accessory respiratory muscles. In addition, the patient had flapping tremor, chemosis and cyanosis in his nails and mucosa. His body temperature was $36.8^{\circ} \mathrm{C}$, arterial blood pressure $110 / 70 \mathrm{mmHg}$, heart rate 110 beats.minute- ${ }^{-1}$ and respiratory rate 40 breaths.minute ${ }^{-1}$. Pulmonary auscultation revealed silent chest in both hemithoraces. There were no heart murmurs, no peripheral oedema and no jugular vein distention. The liver and spleen were not palpable. The abdomen was soft and flat without tenderness or rigidity.

\section{Investigations}

The initial laboratory studies revealed the following: leukocyte count 10,000 cells $\mathrm{L}^{-1}$ with $76 \%$ neutrophils; haemoglobin $11.6 \mathrm{~g} \cdot \mathrm{dL}^{-1}$; haematocrit 35.7\%; and platelet count 241,000 cells. $\mathrm{L}^{-1}$. The prothrombin time and activated partial thromboplastin time were within normal limits. Erythrocyte sedimentation rate was 32 $\mathrm{mm} \cdot$ hour $^{-1}$. His blood chemistries were within normal limits.

The results from arterial blood gas analysis on room air are shown in table 1.

Chest radiography taken in the emergency department revealed bilateral hyperlucency of the lung fields, especially in the basal areas.

\section{Table $1 \quad$ Arterial blood gas results at different treatment times}

\begin{tabular}{|lccccc|}
\hline & $\mathrm{pH}$ & $\mathrm{Pa}_{1} \mathrm{CO}_{2} \mathbf{~} \mathbf{m H g}$ & $\mathrm{Pa}_{1} \mathbf{O}_{2} \mathbf{m m H g}$ & $\mathrm{HCO}_{3} \mathbf{m E q} \cdot \mathbf{L}^{-1}$ & $\mathrm{Sa}_{1} \mathbf{O}_{2} \%$ \\
On room air & 7.41 & 47 & 39 & 34 & 73 \\
With nasal $\mathrm{O}_{2}$ & 7.36 & 72 & 49 & 41 & 80 \\
With BiPAP and $\mathrm{O}_{2}$ & 7.41 & 43 & 69 & 34 & 89 \\
\hline
\end{tabular}

$\mathrm{Pa}_{1} \mathrm{CO}_{2}$ : arterial carbon dioxide tension; $\mathrm{Pa}_{1} \mathrm{O}_{2}$ : arterial oxygen tension; $\mathrm{Sa}_{1} \mathrm{O}_{2}$; arterial oxygen saturation; BiPAP: bilevel positive airway pressure. $1 \mathrm{mmHg}=0.133 \mathrm{KPa}$.

\section{N. Dursunoglu \\ S. Baser \\ G. Kiter \\ S. Özkurt \\ F. Evyapan}

Pamukkale University Medical Faculty

Pulmonary Diseases Dept

Denizli

Turkey

\section{Correspondence:}

N. Dursunoglu

Pamukkale Universitesi Tip

Fakultesi

Gogus Hastaliklari A.D. Kinikir

20200

Denizli

Turkey

Fax: 902582134922

E-mail:

ndursunoglu@yahoo.com
Task 1

Interpret the results of arterial blood gases taken at room air from table 1. 


\section{Answer 1}

This analysis revealed type II hypercapnic hypoxic respiratory failure.

\section{Clinical course}

The patient was taken into the intensive care unit and given bronchodilator therapy. Corticosteroids, antibiotic treatment and nasal $\mathrm{O}_{2}$ at 2 L.minute- ${ }^{-1}$ was subsequently initiated. Under this treatment, the patient developed a tendency for sleep, and deterioration of blood gases was observed (table 1).

\section{Task 2 \\ Considering the clinical picture described and the arterial blood gas results found with $\mathrm{O}_{2}$ therapy, what is your diagnosis?}

At this stage, non-invasive positive pressure ventilation (NPPV) was initiated, with a fraction of inspired oxygen of 1 , a positive end-expiratory pressure of $5 \mathrm{cmH}_{2} \mathrm{O}$ and a pressure-support level of $10 \mathrm{cmH}_{2} \mathrm{O}$ with nasal bilevel positive airway pressure (BiPAP) (Respironics Inc, Murrysville, PA, USA). Approximately 1 hour after this treatment, a significant improvement was seen in the patient's clinical appearance and arterial blood gases improved (table 1). BiPAP treatment was maintained for 24 hours over the first few days.

During the 4th day of treatment, haemoptysis appeared. A new lesion was noticed on chest radiography (figure 1) and on thoracic high-resolution computerised tomography (HRCT) (figure 2).

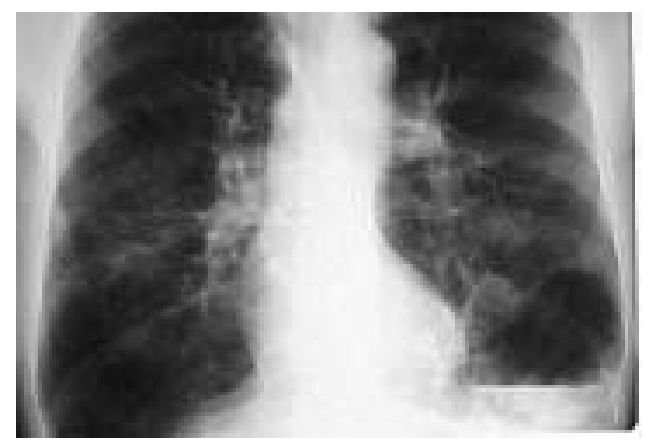

Figure 1

Chest radiography.

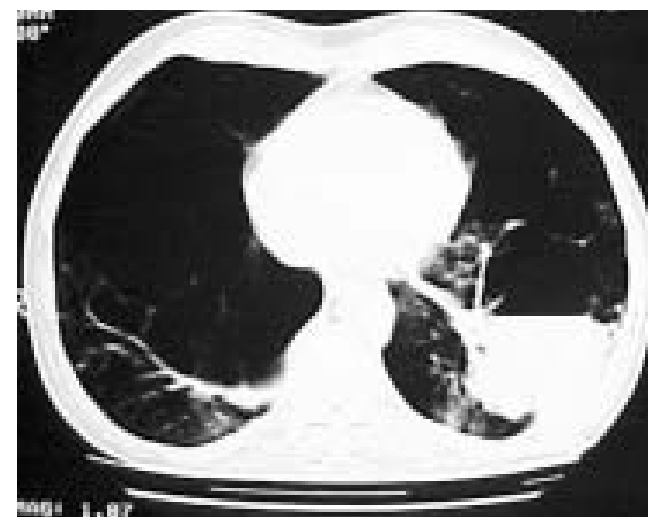

Figure 2

HRCT.

\section{Task 3}

What is your interpretation of the lesion in figure 1 ?

Task 4

What is your interpretation of the lesion in figure 2?

Task 5

What are your differential diagnoses? 


\section{Answer 3}

Chest radiography revealed an air-fluid level above the diaphragm in the left lower lobe.

\section{Answer 4}

HRCT revealed an air-fluid level in a bulla in the posterior segment of the left lower lobe.

\section{Answer 5}

The differential diagnoses should include lung abscess, pulmonary tuberculosis, pulmonary fungal disease, cavitary lung carcinoma and pulmonary haemorrhagia within a bulla.

Blood clots were discovered on the left bronchial tree, and a haemorrhagic area on the superior segment of the left lower lobe was observed using fibreoptic bronchoscopy. BiPAP treatment was stopped because of this complication. Haemoptysis and the radiographic findings resolved within a few days (figures 3 and 4). The patient was discharged from hospital with bronchodilator medication and long-term oxygen therapy. His last arterial blood gases taken with nasal $\mathrm{O}_{2}$ were: $\mathrm{pH} 7.43 ; \mathrm{Pa}_{1} \mathrm{CO}_{2} 43 \mathrm{mmHg}$; and $\mathrm{Pa}_{1} \mathrm{O}_{2} 70 \mathrm{mmHg}$. Final pulmonary function tests were as follows: forced vital capacity (FVC) 1,300 $\mathrm{mL}(40 \%)$; forced expiratory volume in one second (FEV1) $700 \mathrm{~mL}(30 \%)$; FEV1/FVC 56\%; peak expiratory flow 1,180 mL (17\%); forced expiratory flow between 25 and $75 \% 350 \mathrm{~mL}(11 \%)$. Analysis of bronchial lavages showed neither malignancy nor acid-fast bacilli.

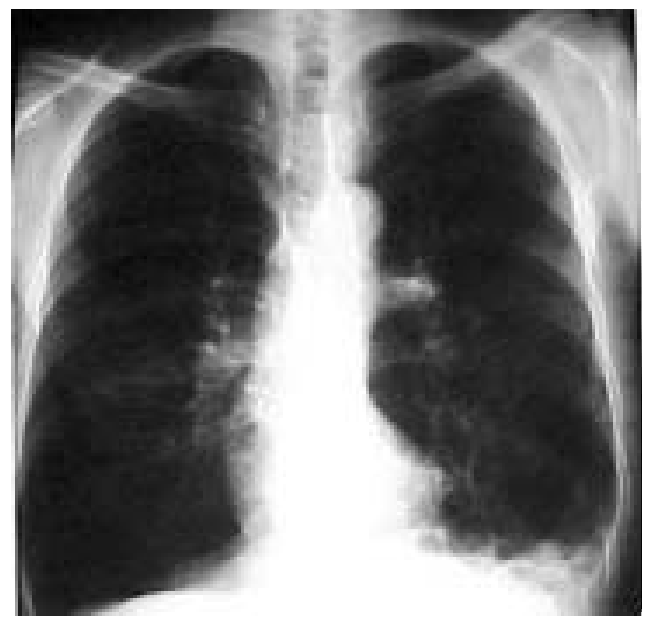

Figure 3

Repeat chest radiography a few days later.

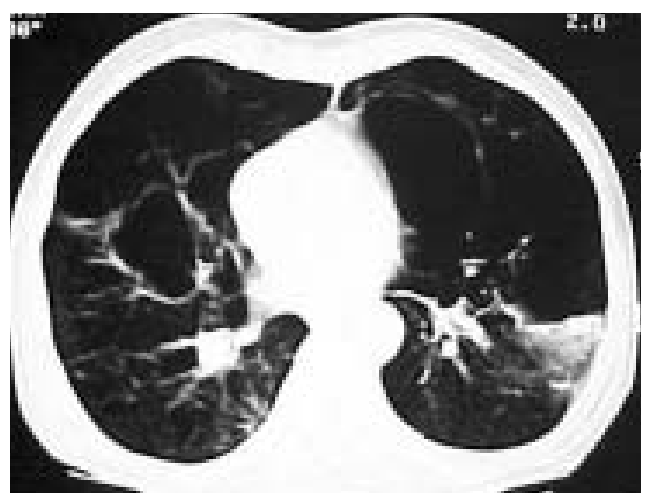

Figure 4

Repeat HRCT a few days later.

\section{Task 6 \\ According to this progress, what is your final diagnosis?}




\section{Answer 6 \\ Pulmonary haemorrhagia within a bulla.}

\section{Discussion}

NPPV using nasal or face masks improves $\mathrm{pH}$ relatively rapidly, at 1 hour after instituting ventilation to manage acute exacerbations of COPD. Thus, it reverses the progression of respiratory failure, reduces morbidity and mortality, and improves minute ventilation, respiratory rate and transdiaphragmatic activity [1-3]. It is suggested that intubation rates and complications associated with the use of mechanical ventilation are also reduced with non-invasive ventilation [4].

In the patient presented in this study, hypercapnic hypoxic respiratory failure developed under standard treatment. Subsequently, NPPV was initiated, and, within hours of this treatment, a significant improvement was seen in both clinical findings and blood gases.

NPPV is safe and well tolerated in most properly selected patients. With NPPV, in both acute and chronic settings, the most commonly encountered problems are related to the interface, air pressure or flow. [5]. Air leakage regularly occurs during sleep, leading to arousals; however, fortunately, gas exchange is usually well maintained [6].

Major complications of NPPV, such as aspiration or pneumothorax, are unusual if patient-selection guidelines are followed [5]. Recently, a very unusual complication related to NPPV was reported by VAN DE Louw et al. [7], which described a case of oesophageal perforation.

In the case presented here, haemoptysis appeared on the 4th day of NPPV treatment, an air-fluid level became visible on chest radiography in the left lower zone, and an air-fluid level within a bulla, previously detected on HRCT, was confirmed. Fibreoptic bronchoscopy was performed and haemorrhagia was observed in the left lower lobe. Although a localised air-fluid level on chest radiography raises the potential of infection [8], the differential diagnoses included lung abscess, pulmonary tuberculosis, pulmonary fungal disease, cavitary lung carcinoma and pulmonary haemorrhagia within a bulla. After cessation of NPPV, all findings confirming haemorrhagia resolved within a few days.

The major complications of bullous disease of the lungs are infection of the bulla, chest pain, haemorrhage, spontaneous pneumothorax and lung cancer [9]. Haemoptysis, which is occasionally massive, can result from rupture of blood vessels within the walls of bullae [10].

In conclusion, NPPV is life saving in acute exacerbations of COPD. However, when initiating this treatment, care should be taken in patients with bullous emphysema, as complications, such as haemorrhagia within a bulla, could occur.

\section{References}

1. Bott J, Carroll MP, Conway JH, et al. Randomized controlled trial of nasal ventilation in acute respiratory failure due to chronic obstructive airway disease. Lancet 1993; 341: 1555-1557.

2. Brochard L, Mancebo J, Wysocki M, et al. Noninvasive ventilation for acute exacerbation of COPD. N Engl J Med 1995; 333: 817-822.

3. Wedzicha JA, Mills PR. Management of acute exacerbations of airway diseases. In: Albert R, Spiro S, Jett J, eds. Comprehensive Respiratory Medicine. Barcelona, Mosby, 1999, 3; pp. 1-38.

4. Kramer N, Meyer TJ, Meharg J, Cece RD, Hill NS. Randomized prospective trial of noninvasive positive pressure ventilation in acute respiratory failure. Am J Respir Crit Care Med 1995; 151: 1799-1806.

5. Hill NS. Complications of noninvasive positive pressure ventilation. Respir Care 1997; 42: 432-442.

6. Meyer TF, Pressman MR, Benditt J, et al. Mouth leakage during nocturnal nasal ventilation. Effect on sleep quality. Am J Respir Crit Care Med 1995; 151: A423.

7. Van de Louw A, Brocas E, Boiteau R, Perin-Gachadoat D, Tenaillon A. Oesophageal perforation associated with noninvasive ventilation. Chest 2002; 122: 1857-1858.

8. Mahler DA, D'Esopo ND. Peri-emphysematous lung infection. Clin Chest Med 1981; 2: 51-57.

9. DesLauriers J, Leblanc P. Management of bullous disease. Chest Surg Clin North Am 1994; 4: 539.

10. Murphy DM, Fishman AP. Bullous diseases of the lung. In: Fishman AP, Elias JA, Fishman JA, eds. Fishmans Pulmonary Diseases and Disorders. New York, Mcgraw-Hill, 1998: pp. 843-849. 